\title{
Photoplethysmographic health monitoring of the driver and Smart Driving Assistant to avoid collisions with vehicles
}

\author{
S C RAJKUMAR ${ }^{1}$
}

${ }^{1}$ Affiliation not available

June 28, 2021

\begin{abstract}
Driving for a long time leads to physical, psychological stress, which increases life at higher risk and puts health in all hostile areas. Spending more time behind the wheel leads to uninterrupted sitting, resulting in obesity, mental health risk, poor sleep, and bad habits such as drug addiction. In this research, reliable emergency services ensure safe driving. Such an experience guarantees continuous monitoring of the driver's health intelligently. An intelligent health system continuously monitors the driver's health status and constantly updates the cloud server to monitor the driver's heart rate. According to a recent study, $60 \%$ of road accidents occur due to the driver's restless continuous driving. On motorways, vehicles are faster than those on the city side, and if a vehicle brakes abruptly without notification, it causes severe damage, followed by escort vehicles. In addition, the driver's health is a crucial factor, and the unexpected worsening of health complications such as stroke and cardiac arrest is unpredictable, as the symptoms are prevalent and occur within minutes. To avoid stressful driving, the intelligent assistant must monitor his health and suggests relaxation guidelines.
\end{abstract}




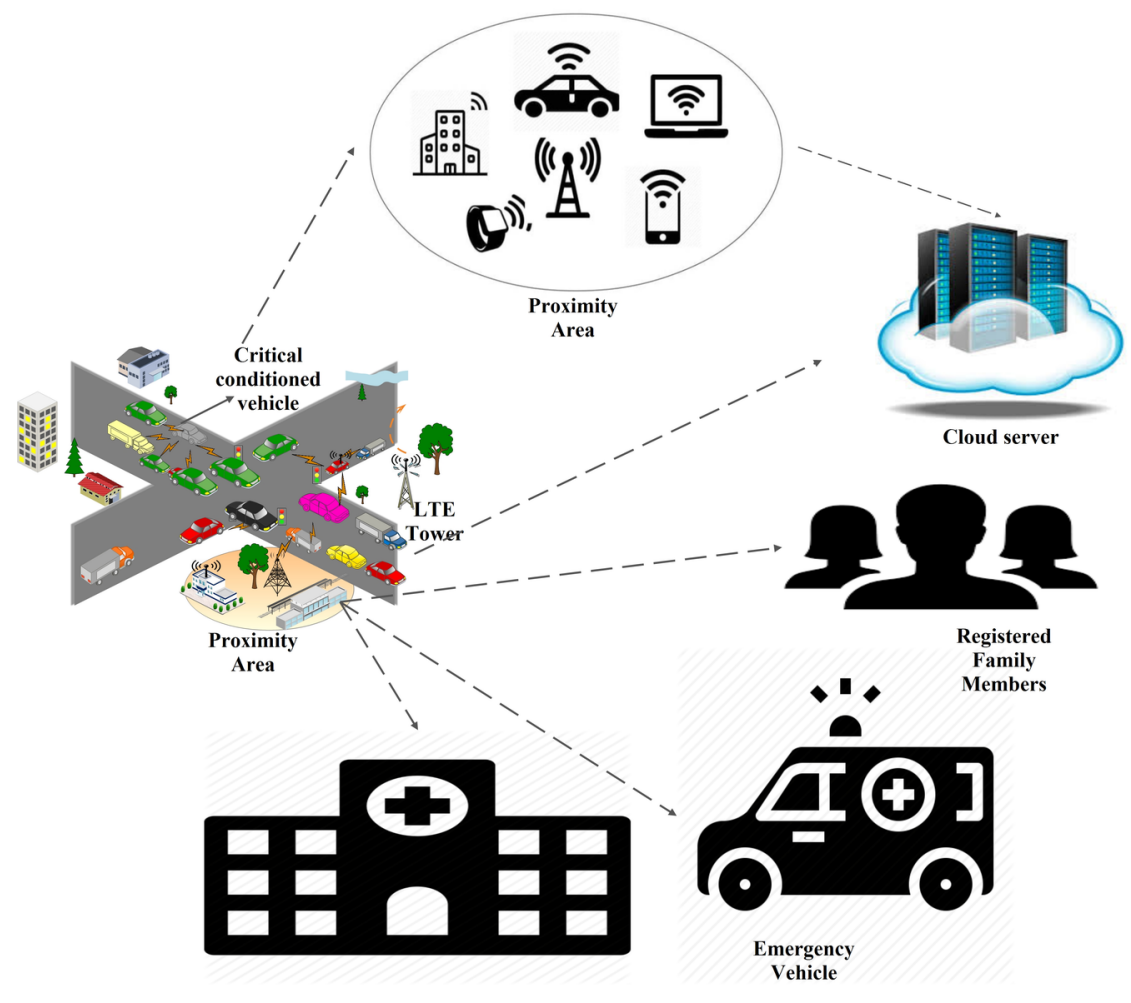

Hospital

Figure 1: System Architecture

\section{Hosted file}

Smart driving assistant to prevent vehicle collisions.pdf available at https://authorea.com/ users/415030/articles/527873-photoplethysmographic-health-monitoring-of-the-driver-andsmart-driving-assistant-to-avoid-collisions-with-vehicles 